\title{
Generic Strategies and Firm Performance: An Investigation of Informal Sector Micro-Enterprises in Kenya
}

\author{
Esther Mungai ${ }^{1} \&$ Madara Ogot $^{2}$ \\ ${ }^{1}$ School of Business, Technical University of Kenya, Nairobi, Kenya \\ ${ }^{2}$ School of Business, University of Nairobi, Nairobi, Kenya \\ Correspondence: Madara Ogot, School of Business, University of Nairobi, Nairobi, Kenya. E-mail: \\ madaraogot@uonbi.ac.ke
}

Received: November 5, 2016

Accepted: January 25, 2017 Online Published: February 22, 2017

doi:10.5539/ijbm.v12n3p148

URL: https://doi.org/10.5539/ijbm.v12n3p148

\begin{abstract}
Micro-enterprises (MEs) have been shown to collectively be the largest employer in most developing countries thus playing a significant role in the countries economies. Using informal sector micro-enterprise furniture makers (wood and metal) in Nairobi, Kenya and based on Porter's competitive business strategies typology, this study sought to determine if the strategies employed by the informal sector MEs fit within the typology framework, and if membership within the strategic groups in the typology are a predictor of better business business performance. From the study, although membership within the two focus strategic groups of differentiation and low cost was confirmed, unlike studies done with medium and large enterprises, membership was not found to be a predictor of better business performance. Porter's typology may therefore not adequately capture the competitive business activities relevant to and directly by MEs, presenting an opportunity for research into the development of competitive business strategy typologies directly derived from their activities and therefore applicable to them.
\end{abstract}

Keywords: competitive business typology, micro-enterprises, business performance, informal sector

\section{Introduction}

In Sub-Saharan Africa (SSA), it is estimated that the informal sector accounts for approximately $90 \%$ of all new jobs (CfA, 2005) and up to 85\% of total employment (World Bank, 2005). The sector consists mainly of micro-enterprises (MEs) that 'typically operate at a low level of organization, with little or no division between labour and capital, and on a small scale.' (ILO, 2000). The importance of the informal sector in the development of these economies is backed by empirical evidence supporting the countries' development, employment, wealth creation and poverty reduction objectives (World Bank, 2004; ILO, 2002). For example, the sector employment in Kenya was estimated at $81 \%$ of total non-agricultural employment in 2015 (KNBS, 2016), mainly in the areas of manufacturing, building and construction; wholesale and retail trade; hotels and restaurants; transport and communications (mainly support services to transport activity); and community, social and personal services.

Despite the significant role the informal sector micro enterprises (IS/MEs) play in SSA national economies, few transition to formal small or medium size enterprises. This may be due to a wide array of challenges faced that include stiff competition, high cost of production, lack of adequate capital, cyclical demand, lack of ready markets, hard bargaining customers, shortage of raw materials, dishonest employees, government regulation, among others (Ogot, 2014). These challenges are further compounded for IS/ME entrepreneurs by low education levels; lack of managerial, marketing and production skills; use of rudimentary technology; low-skilled work-base; and very low purchasing power of their consumers/clients (Stevenson \& St-Onge, 2005). Further, previous research has often treated the informal sector as a composite of homogenous activities not being able to play a meaningful development role. This study seeks to address this gap identified in the literature by disaggregating and investigating different activities in the informal sector so as to enable their impact on income and employment be better studied (Otoo et al., 2012).

This study sought to determine which competitive business strategies, based on the dominant business strategy theories from the strategic management literature, lead to better performance among furniture making micro-enterprises. Applicability and adoption of successful strategies typically applicable to large and medium 
enterprises may start to address and overcome the myriad of previously enumerated challenges faced by IS/MEs, enabling their transition to formal small and medium enterprises and strengthening their countries' economies. Although the focus of this paper is on furniture making IS/MEs in Kenya, the results may find broader applicability to other MEs in developing, transition and developed countries.

From the literature, two classes of business strategy theories dominate: resource-based and activity-based theories. Resource-based theories focus on the enterprises internal dynamic competencies and the external environment as the key drivers of success (Masakure et al., 2009; Wernerfelt, 1984). An enterprise seeks to exploit relevant resources that are valuable, rare, difficult to copy or to substitute, giving it a competitive advantage (Locket \& Thompson, 2001). Masakure et al., 2009 applied the resource-based view (RBV) to investigate the financial performance of micro-enterprises in Ghana. They found that firm performance was impacted by firm-specific resources coupled with sector and market factors. Boohene (2009) used the RBV framework to investigate the relationship between gender, strategic capabilities and performance of small firms in Ghana, with results showing that gender of the owner managers directly influences business performance, resources and skills. Otoo et al. (2012) also used the RBV framework to investigate factors affecting the success of women street vendors in Niger.

For activity-based theories, those of or based on Porter $(1980,1985)$ dominate the literature (e.g. Kim et al. 2004, Spanos et al. 2004, Pertusa-Ortega et al. 2009). The efficacy of these theories and derived models have been extensively empirically demonstrated over the years through research carried out on medium and large enterprises in developed countries, mainly in the Americas, Europe and Asia. Although these theories appear to be readily applicable to the informal sector, limited research has been done on IS/MEs in Sub-Saharan Africa. Examples of studies investigating the performance of micro and small enterprises based on adoption of Porter's competitive business strategies include a study on the light manufacturing enterprises in Zimbabwe (Chadamoyo \& Dumbu, 2012), investigation of the strategic responses of micro and small restaurants in Nairobi to their competition based on Porter's (1980, 1985) Five Forces Model (Muriuki, 2013), investigation of competitive strategies and business environment's influence on small enterprises in China (Yan, 2010) and in Austria (Leitner \& Guldenberg, 2010).

The activity-based theories were selected as the theoretical framework for this study. This work contributes to the literature by establishing the extent to which Porter-based activity theories are being applied by manufacturing IS/MEs in Kenya, and establish if conclusions derived from studies on medium and large enterprises hold.

\section{Literature Review}

This section begins with a discussion on the formal/informal sector dichotomy placing the IS/MEs in context. This is followed by a discussion of the Porter-based competitive business typology and its potential applicability to micro-enterprises.

\subsection{Informal Sector}

Research interest in the informal economy has fluctuated over the past four decades. There has recently, however, been renewed interest in it for two main reasons. First, the informal economy has continued to grow worldwide despite early predictions of its decline, and second, it is beginning to be recognized as key to the promotion of growth and reduction of poverty (Chen, 2005). The Kenya Government (KNBS, 2016) defines the informal sector to 'cover all small- scale activities that are semi-organized, unregulated, and use low and simple technologies.' According to the International Labour Organization (ILO), enterprises in the informal sector 'typically operate at a low level of organization, with little or no division between labour and capital, and on a small scale.' (ILO, 2000).

There are three dominant schools of thought with regard to the informal sector: the dualist, structuralist and legalist schools (Chen, 2005). Advocated by the International Labour Organization in the 1970s, the dualist school views the sector as a result of lack of formal job opportunities to absorb surplus labour, and comprises of marginalized (distinct and unrelated to the formal sector) activities among the poor, providing a safety net in times of crisis (ILO, 1972, Tokman, 1978). Put forth in the 1980s, the structuralist school viewed the sector as subordinated economic units (micro firms) and workers that increase the competitiveness of large capitalist firms by serving to reduce their input and labour costs. The legalist view emerged in the late 1980s and 1990s and viewed the sector as comprising of micro-entrepreneurs who choose to remain informal in order to avoid the costs, time and effort of formalization (de Soto, 1989).

In the recent past, a consensus view combining elements from the dualist, legalist and structuralist views has 
emerged based on the idea of a multi-segmented labour market (Chen 2005). It posits that the informal economy is comprised of three main segments, a lower, middle and upper-tier (Bacchetta et al., 2009). '... a lower-tier segment dominated by households engaging in survival activities with few links to the formal economy, as dualists suggest; an upper-tier segment with micro-entrepreneurs who choose to avoid taxes and regulations, as the legalists suggest; and an intermediate segment with micro-firms and workers subordinated to larger firms, along the lines suggested by structuralists. [...] Depending on the regions or countries, the relative importance of each of the segments may vary, making one or other of the three views more relevant.' (p. 42)

Maloney (2004) posits that 'the informal sector [should be seen] as the unregulated, developing country analogue of the voluntary entrepreneurial small firm sector found in advanced countries, rather than a residual comprised of disadvantaged workers rationed out of good jobs.' Further, Kinyanjui (2007) argues that efforts to formalize and legalize enterprises in the sector, especially in SSA, have not worked. Instead, the values and intrinsic structural characteristics of the emergent production systems in the sector should be studied and better understood, as the sector continues to define itself by extending its frontiers and markets, forming new businesses and expanding spatially. The theoretical framework for this study, therefore, is based on the emerging consensus school of thought, focussing on micro-enterprises in the intermediate and upper-tier segments, with a view to getting a better understanding the sector through the prism of activity-based business strategy theories.

\subsection{Generic Competitive Business Strategies}

Competitive business strategy typologies provide classifications of business strategies according to common elements. They are typically used in deriving business strategy from competitive industry analysis in the formal economy with a view to to gaining competitive advantage over ones rivals. In the strategic management literature, two theories dominate, resource-based theories and activity-based theories. For activity-based theories, those of or based on Porter $(1980,1985)$ dominate the strategic management literature. Porter settled on three key generic strategies that a business can adopt: cost leadership, product differentiation or market focus. The three strategies can be characterized along two dimensions of competency (cost or differentiation) and market scope (focused or broad). Each dimension represents two independent decisions an enterprise can make: (1) how they would like to compete (through cost or differentiation), and (2) where to complete (market scope). The focus strategy, therefore, is not a true decision on competitive advantage, but about market scope (Pertusa-Ortega et al., 2009).

The cost leadership strategy aims to have the lowest price in the target market. To achieve this, while remaining competitive, companies following this strategy must be able to operate at costs lower than their competitors. Differentiation strategies seek to earn above average returns by creating brand loyalty. The latter can serve as a strong entry barrier to competitors. Finally, focus strategies target segments of the market whether a specific consumer group, product line or geographic area. Porter's generic strategies typology have been widely accepted by researchers who posit that companies are more likely to pursue 'hybrid', 'mixed', 'integrated' or 'combination' strategies, leading to superior performance rather than pursuit of a single generic strategy (Kim et al. 2004; Spanos et al., 2004).

The development of Porter and Porter-based activity-based business strategy typologies are derived primarily from studies of medium and large enterprises (MLEs) in the formal sector. Numerous studies in the literature that have sought to establish the validity and applicability of the typology have also been based on formal sector MLEs (Beal \& Yasai-Ardekani 2000; Kim et al., 2004; Spanos et al., 2004; Pertusa-Ortega et al., 2009). The ability to establish cost leadership or differentiation leadership may be beyond the ability of micro and small enterprises who have neither the resources nor clout to dominate a market segment vis-a-vis their larger competitors. They may therefore be restricted, if at all, to the strategies embodied within the focus dimension.

This study therefore sought to (1) empirically determine if the advocated strategies within the focus dimension are utilized by IS/MEs, and (2) establish if their use leads to improved business performance. The outcome from this research contributes to the small business literature by providing empirical evidence on the extent of the applicability of formal sector activity-based business strategies to manufacturing IS/MEs in Nairobi, Kenya.

\section{Conceptual Model and Research Hypotheses}

Due to their size IS/MEs can neither be overall cost nor differentiation leaders in the market. They may be limited to strategies within the focus dimension either as focus differentiation and/or focus low cost. Note that strategic groups can be developed from multivariate measures of intended or implemented strategies, and provide a framework for empirically demonstrating that strategies differ among enterprises, and that better strategies lead to better performance. Demonstration, therefore, of the ability of multivariate measures of strategic choice to classify enterprises into homogenous groups based on Porter's typology will provide empirical evidence of the 
construct applicability to IS/MEs. For this study, due to general lack of documentation on or the existence of intended strategy among IS/MEs - typically through documented strategic plans, implemented strategy was used. The multivariate measures for the strategic groups were based on the competitive business activities most closely aligned to each of two generic strategic groups of focus differentiation and focus low cost.

The conceptual framework for the study is presented in Figure 1. The competitive business methods employed by the IS/MEs constitute the independent variables; membership within the stated strategic groups constitutes the intervening variables; and business performance, measured through revenue growth, forms the dependent variable.

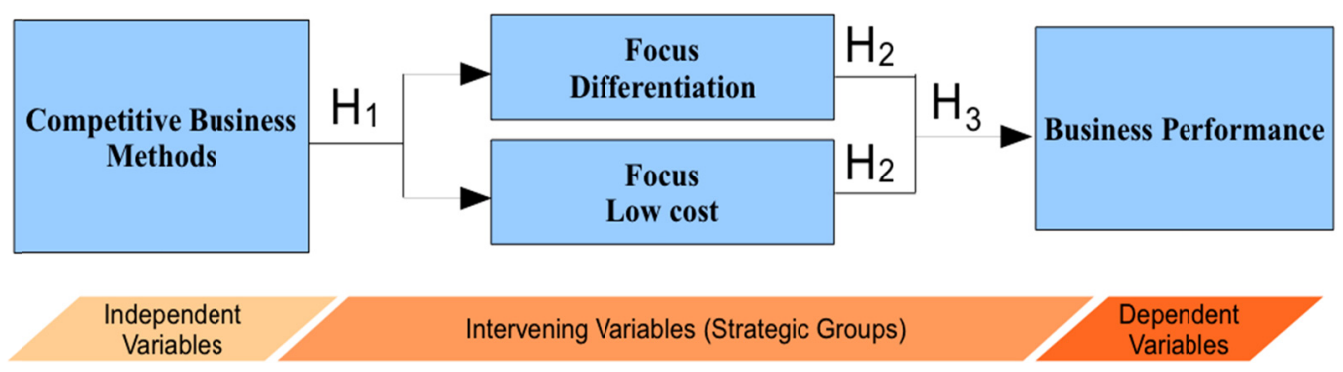

Figure 1. Conceptual framework

The first hypothesis focuses on the applicability to IS/MEs of the strategic groups defined by Porter's typology

$\mathrm{H}_{1}$ : The focus dimension can serve as determinants of strategic group membership among IS/MEs.

Further, as discussed previously, studies on MLEs found that those companies not employing any of the defined strategies had generally worse performance than those adopting pure or mixed strategies. Will these conclusions still hold true within the focus dimension when applied to IS/MEs? This will be answered by testing the following two hypotheses:

$\mathrm{H}_{2}$ : MEs employing pure strategies will result in better performance than those not employing any.

$\mathrm{H}_{3}$ : MEs employing mixed strategies will result in better performance than those not employing any.

\section{Sampling and Data Analysis}

The study drew on primary data from IS/MEs in the furniture manufacturing (wood and metal works) in Nairobi, Kenya. Secondary research material was used for the development of the research instrument. A major challenge was the difficulty in accurately determining the population size as a majority of the target population falls within the informal sector. Stratified purposeful sampling was therefore used in six representative regions of Nairobi with high concentrations of IS/MEs: Eastlands, Westlands, Nairobi West, Ngara/Parkroad area, Dagoretti Corner/Kawangware and Kangemi. Stratification ensured an equal proportion of manufacturing IS/MEs are included in the sample from each of the representative areas. Using Cochran's (1977) sample size equation for scaled data and populations greater than 10,000, the minimum sample size was calculated 119 for a desired accuracy level of $95 \%$ and margin of error of $3 \%$. The survey data collection method was used. However, to account for surveys that may not be returned or completed properly, oversampling was used yielding a sample size of 135.

The research instrument was inductively derived to be able to evaluate the extent to which MEs in the informal sector employ each of the competitive business activities that define the two generic strategies of focus differentiation and focus low cost. Respondents were asked to rate on a 4-point Likert-type scale the extent to which they employed each of the different strategies as expressed in Table 1 with 4-All the time, 3-Often, 2-Occasionally and 1-Never. The statements were based on the competitive business activities seen to be most closely aligned with the differentiation and cost leadership strategic groups as tabulated by Dess \& Davis (1984). Descriptive statistics were first used to provide comparisons and contrasts between the strategic groups, while inferential statistics were used for the hypotheses testing. For testing the first hypothesis cluster analysis was used on the data to establish the extent to which the MEs employed the competitive business methods associated with each of the strategic groups. 
Table 1. Statements associated with each of the strategic group competitive business strategies and rated by the respondents on a likert-type scale

Statements Associated with the Differentiation Focus Statements Associated with the Low Cost Focus Strategies

Strategies

D1. I try to make sure that my products can be $\mathrm{C} 1$. I change my source of raw materials to the supplier who will give me distinguished from those of my competitors so as to the lowest price at the time of order

increase sales $\quad$ C2. I try to make sure that the selling price of my products are lower than D2. I continuously come up with new products to those offered by my competitors

offer my customers so I can be a step ahead of my C3. I try to make sure that I reduce wastage during my manufacturing competitors process so I can offer my customers lower prices and therefore beat my D3. I buy my raw materials used to manufacture competition

my products from the same set of suppliers $\quad$ C4. I try to make sure that I reduce wastage during my manufacturing D4. I try to target my products to a particular type process so I can make more profit

of customer

C5. I try to improve my manufacturing process so that I can use less

D5. I focus on only a small number of different material or be able to produce my products quicker

furniture items

C6. When I hire carpenters/artisans, I look for those who already have experience

Source: Based on Dess and Davis (1984)

Cluster analysis, however, does not explicitly provide acceptable or unacceptable solutions. It structures the data so that relationships may emerge, a process that is by design both subjective and objective, necessitating the $a$ priori explicit determination of the criteria to be used in solution selection. One of the objective criterions was calculating the F-Value using a one-way ANOVA, to determine the significance of the clustered solutions. Determination of the location of the differences between all mean pairs was done using Scheffe's posterior contrast test that is readily applicable to groups of unequal sizes. It is also relatively insensitive to departures in normality and homogeneity of variances. A similar approach was used by Dess and Davis (1984) and Mungai and Ogot (2012).

Enterprises were considered to be members of a strategic group if they gave at least two of the corresponding statements within the group as were presented in Table 1 a rating of 4 . With reference to Equations (1) and (2), the extent of membership within each group was measured by calculating the deviation of an enterprise's overall average score for all the statements corresponding to each of the strategic groups, from the strategic group centroid location taken as 3 (from the 1-4 Likert Scale). It was assumed that average scores $>3$ correspond to group membership and scores $=<3$ do not.

$$
\begin{gathered}
D_{\mathrm{di}}=\left(d_{1 \mathrm{i}}+d_{2 \mathrm{i}}+d_{3 \mathrm{i}}+d_{4 \mathrm{i}}+d_{5 \mathrm{i}}\right) / 5-3 \\
D_{\mathrm{ci}}=\left(c_{1 \mathrm{i}}+c_{2 \mathrm{i}}+c_{3 \mathrm{i}}+c_{4 \mathrm{i}}+c_{5 \mathrm{i}}+c_{6 \mathrm{i}}\right) / 6-3
\end{gathered}
$$

where $D_{\mathrm{di}}, D_{\mathrm{ci}}, d_{\mathrm{ji}}$, and $c_{\mathrm{ki}}$ are the deviation from the differentiation strategic group centroid for the $\mathrm{i}^{\text {th }}$ respondent $(i=1, \ldots, 45)$, the deviation from the low cost focus strategic group centroid for the $\mathrm{i}^{\text {th }}$ respondent, rating on the $\mathrm{j}^{\text {th }}$ $(\mathrm{j}=1, \ldots, 5)$, differentiation focus statement by $\mathrm{i}^{\text {th }}$ respondent, and the rating on the $\mathrm{k}^{\text {th }}(\mathrm{k}=1, \ldots, 6)$ low cost focus statement by $\mathrm{i}^{\text {th }}$ respondent, respectively.

Testing of the second and third hypotheses were done by calculating the F-Value using a one-way ANOVA, to determine if there is a significant difference, based on business performance measured by normalized revenue growth, between those enterprises who are and are not members of the strategic groups. Determination of the location of the differences between all mean pairs was again done using Scheffe's posterior contrast test.

Respondents were asked to provide gross revenues for 2009, 2010 and 2011. The latter were estimates as the survey was carried out between September and October 2011, before the end of the year. Annualized revenue growth was then calculated by averaging the percent growth between 2009 to 2010, and between 2010 and 2011 . Growth rates where then normalized between -5 to 5 .

\section{Results}

All 135 administered questionnaires were returned by the respondents. One of the key elements in the study was comparing business performance between strategic groups. Many IS/MEs owners, however, were reluctant to provide financial data resulting in only 45 questionnaires where all sections were answered completely. Table 2 
presents the mean revenues for the requested period, the average age and the average number of employees of the businesses sampled. Contained within the same table are the respective standard deviations, minimum and maximum values.

Table 2. Descriptive statistics on business performance, enterprise age and number of employees $(n=45)$

\begin{tabular}{|c|c|c|c|c|c|}
\hline & \multicolumn{3}{|c|}{ Revenue (Kshs. Millions) } & \multirow{2}{*}{$\begin{array}{l}\text { Age } \\
\text { (Years) }\end{array}$} & \multirow{2}{*}{$\begin{array}{l}\text { Number } \\
\text { Employees (*) }\end{array}$} \\
\hline & 2009 & 2010 & 2011 (Estimate) & & \\
\hline Mean & 4.27 & 3.2 & 4.75 & 5.6 & 6 \\
\hline Stand. Dev. & 2.11 & 0.8 & 1.25 & 3.2 & 3.54 \\
\hline Min. & 2.3 & 2.4 & 3.5 & 2 & 2 \\
\hline Max. & 7.2 & 4 & 6 & 20 & 20 \\
\hline
\end{tabular}

(*) Although three firms in the sample had employee numbers exceeding the defined ME upper bound of 10, with 16, 16 and 20 employees, they were retained.

To test for validity of the statements used to determine membership in the two strategic groups, correlation analyses where conducted between the results from the statements within each of the groups. Table 3 presents the results from the Pearson's correlation tests between pairs of statements defining membership in the differentiation strategic group. For members that show high correlation, one of the statements in the pair could be ignored without loss of information. From the results, however, none of the statements are significantly correlated with each other, and therefore all shall be retained as a measure of group membership. Similarly with reference to Table 4, there is low correlation between results from all the statements under the low cost focus group, and the statements are therefore all retained.

Table 3. Pearson's correlation coefficients for differentiation focus statements

\begin{tabular}{|c|c|c|c|c|}
\hline & D2 & D3 & D4 & D5 \\
\hline D1 & 0.1725 & -0.0059 & 0.1377 & -0.3032 \\
\hline D2 & & -0.0088 & 0.0765 & -0.1615 \\
\hline D3 & & & -0.0575 & 0.1356 \\
\hline D4 & & & & 0.0219 \\
\hline
\end{tabular}

Table 4. Pearson's correlation coefficients for low cost focus statements

\begin{tabular}{|c|c|c|c|c|c|}
\hline & $\mathrm{C} 2$ & $\mathbf{C 3}$ & $\mathrm{C} 4$ & C5 & C6 \\
\hline C1 & 0.1282 & -0.1350 & 0.1580 & 0.1604 & 0.1957 \\
\hline $\mathrm{C} 2$ & & -0.3579 & 0.1511 & 0.0718 & -0.1970 \\
\hline C3 & & & 0.1952 & 0.0306 & 0.3036 \\
\hline $\mathrm{C} 4$ & & & & 0.2291 & 0.3513 \\
\hline C5 & & & & & 0.2839 \\
\hline
\end{tabular}

Hypotheses 1: The focus dimension in Porter's CBS typology can serve as determinants of strategic group membership among $\mathrm{MES}$

As was presented earlier, the businesses where clustered based on the extent to which they used the stated strategies. A rating of 4 on at least two statements within the strategic group implies membership within the group. Four clusters where thus identified: pure differentiation with group membership only in the differentiation focus strategic group; pure low cost with group membership only in the low cost focus strategic group; mixed 
strategies with group membership in both the differentiation and low cost focus strategic groups; and stuck-in-the-middle with enterprises not belonging to either of the strategic groups. Table 5 summarises the profiles of the four clusters. Centroid deviations for the differentiation focus and low cost focus strategic groups were calculated from Equations 1 and 2, respectively. Also contained within the table are the number of enterprises per cluster, and their respective average performance as measured by the normalized revenue growth.

One-way ANOVA using Scheffe's posterior tests to determine F-values where done separately on enterprises within each clusters emphasis on the low cost focus or differentiation focus strategies, to establish if the clusters are significantly different. The results are presented in Table 6 . Starting with emphasis on differentiation focus strategies, all the clusters show significant difference with each other at $p<0.003$, except for the differentiation focus and mixed strategies clusters, where there is no significant difference. This result is expected as enterprises in both clusters adopt differentiation focus strategies. Within the same table when the emphasis is on low cost focus strategies, all the clusters show significant difference with each other at $p<0.0000$, except for the low cost focus and mixed strategies. As was stated previously, this is expected as enterprises in both clusters adopt low cost focus strategies. Overall, the tests show that the differences between the clusters are significant.

Further, with reference to Table 5, only clusters 1 and 3 showed a positive centroid deviation for enterprises with an emphasis on focus differentiation strategies. This lends support to membership in the focus differentiation strategic group by enterprises in the two clusters. In addition, only clusters 2 and 3 showed a positive deviation for enterprises emphasizing low cost focus strategies, supporting membership in that strategic group. It is worth noting that cluster 3 enterprises collectively had positive centroid deviation for enterprises emphasizing both types of strategies, implying membership in both strategic groups. In other words enterprises in this cluster can be considered to be pursuing mixed strategies. Conversely, cluster 4 enterprises collectively resulted in negative centroid deviation for both emphases, implying lack of membership in either strategic group. Enterprises in this cluster, may therefore be considered 'stuck-in-the-middle', i.e. not actively pursuing either a focus low cost or a focus differentiation strategy. In summary, therefore, hypothesis 1 is supported.

Table 5. Deviations from centroids, and normalized performance for the generic strategy clusters

\begin{tabular}{|c|c|c|c|}
\hline & $\begin{array}{l}\text { Mean Cluster Centroi } \\
\text { (Standard Deviation) } \\
\text { Focus Differentiation }\end{array}$ & Focus Low Cost & $\begin{array}{l}\text { Mean Normalized } \\
\text { Performance } \\
\text { (Standard Deviation) }\end{array}$ \\
\hline Cluster 1: $n=5$ & 0.08 & -0.633 & 3.250 \\
\hline Pure differentiation focus & $(0.240)$ & $(0.452)$ & $(1.397)$ \\
\hline Cluster 2: $n=16$ & -0.450 & 0.281 & 0.922 \\
\hline Pure low cost focus & $(0.320)$ & $(0.255)$ & $(0.719)$ \\
\hline Cluster 3: $n=17$ & 0.082 & 0.255 & 0.941 \\
\hline Mixed Strategies & $(0.329)$ & $(0.348)$ & $(1.211)$ \\
\hline Cluster 4: $n=7$ & -0.371 & -0.286 & 1.519 \\
\hline Stuck-in-the-middle & $(0.249)$ & $(0.477)$ & $(2.411)$ \\
\hline
\end{tabular}

Table 6. ANOVA using Scheffe F-test for Differences between clusters based on centroid deviations ( $p$-values in brackets)

\begin{tabular}{llllllll}
\hline & \multicolumn{2}{c}{ Differentiation Focus Emphasis } & \multicolumn{3}{c}{ Low Cost Focus Emphasis } \\
& Cluster 2 & Cluster 3 & Cluster 4 & Cluster 2 & Cluster 3 & Cluster 4 \\
\hline Cluster 1: Pure differentiation focus & 202.417 & 0.0040 & 112.432 & 342.367 & 327.512 & 37.867 \\
& $(0.0000)$ & $(0.99960$ & $(0.0000)$ & $(0.0000)$ & $(0.0000)$ & $(0.00000$ \\
Cluster 2:Pure low cost focus & & 441.853 & 5.6864 & & 0.61478 & 168.180 \\
& & $(0.0000)$ & $(0.0024)$ & & $(0.6094)$ & $(0.0000)$ \\
Cluster 3: Mixed & & & 193.131 & & & 155.700 \\
& & & $(0.0000)$ & & & $(0.0000)$ \\
\hline
\end{tabular}

Hypotheses 2: Within the focus dimension of Porter's CBS typology, MEs employing pure strategies will result in 


\section{better performance than those not employing any}

Normalized performance for each of the enterprises clusters was presented in Table 7. A one-way ANOVA using Scheffe F-Tests was done on all the clusters pairs with the results presented in Table 4. From the paired tests between cluster 1 (pure differentiation) and cluster 4 (stuck-in-the-middle), as well as cluster 2 (pure cost) and cluster 4 , it is evident that there is no significant difference between the performance of enterprises pursing pure strategies, and those not pursuing any. Hypothesis 2 is therefore not supported.

Hypotheses 3: Within the focus dimension of Porter's CBS typology, MEs employing mixed strategies will result in better performance than those not employing any

Again with reference to Table 7, an ANOVA was done between cluster 3 (mixed strategies) and cluster 4 (stuck-in-the-middle). From the results it is evident that there is no significant difference between the performance of enterprises pursing mixed strategies, and those not pursuing any. Hypothesis 3 is therefore not supported.

Table 7. ANOVA using Scheffe F-test for Normalized Performance Differences between Clusters ( $p$-values in brackets)

\begin{tabular}{llll}
\hline & Cluster 2 & Cluster 3 & Cluster 4 \\
\hline Cluster 1: Pure differentiation focus & 3.72339 & 3.71290 & 1.57567 \\
& $(0.0186)$ & $(0.0188)$ & $(0.2099)$ \\
Cluster 2: Pure low cost focus & & 0.00057 & 0.313245 \\
& & $(0.9998)$ & $(0.8157)$ \\
Cluster 3: Mixed & & 0.29834 \\
& & & $(0.8264)$ \\
\hline
\end{tabular}

\section{Discussion}

This study sought to determine the suitability of Porter's competitive business strategies typology to IS/MEs based on micro-enterprise furniture manufactures (metal and wood) in Nairobi, Kenya. From a review of the literature it became apparent that Porter's model may only be applicable along the focus dimension as IS/MEs cannot become industry leaders either from a differentiation or a low cost perspective due to their very small size. With a relatively small sample of 45 completely filled questionnaires, the following observations can be made. First, the assertion that IS/MEs can be members of the strategic groups of focus differentiation and focus low cost is largely supported. From the sample, only $15.5 \%$ of the enterprises were in the so called 'stuck-in-the-middle' cluster, i.e., placing an emphasis on neither of the two strategies. The applicability of Porter's model to IS/MEs, however, begins to unravel when comparisons are made between the business performances of the different clusters. Neither of the two hypotheses positing that pursing pure or mixed strategies lead to better performance than pursing none was supported. It is worth noting that this lack of support may have been influenced by the small sample size. However, similar often cited studies, for example Dess and Davis (1984), Calori and Ardisson (1988), Herbert \& Deresky (1987) had smaller sample sizes of 15, 30 and 34, respectively. Further, revenue figures provided for MEs are not always completely reliable due to a general lack of keeping of accurate records. A lot of historical data presented, therefore, tend to be 'best guesses', making inferences from this particular measure difficult.

It is interesting to note, however, that enterprises who pursued pure differentiation focus strategies had much higher revenue growth than those pursuing pure low cost focus (at $p=0.0186$ ) or mixed (at $p=0.0188$ ) strategies. Coupled with the observation that only $49 \%$ of the enterprises pursued either a pure differentiation focus (11\%) or mixed (38\%) strategies, the higher revenue growth result supports a general view that although micro entrepreneurs acknowledge the importance of differentiation on business success, few actually implement it. For example in a recent study of the micro-enterprise sector in urban French West Africa, Roy and Wheeler (2006) lament that 'most products were largely undifferentiated in terms of price, quality or other attributes. A significant number of MEs sold exactly the same product, at the same price, in the same location.' (p. 457). This may be due to the risk associated with differentiation. Development of new products and services in order to differentiate or innovate requires commitment of additional resources. Should the product or service, fail in the market, the damage to the ME could be significant. Most entrepreneurs in this sector, therefore, tend to work 
with much safer, proven products and services, albeit with lower profit margins (Roy and Wheeler, 2006).

\section{Conclusion}

From the literature, competitive business strategies and methods employed by IS/MEs are quite diverse. Two general approaches, however, dominate: value chain approaches, and horizontal linkages and networks. Linkages are cooperation between firms seeking to integrate some of their activities, exploit their complementarities in search of new markets, and pool sources of knowledge in order to achieve economies of scale or address common problems (Barkley \& Henry, 2007).

ME participation in value chains involves vertical (forward and backward) linkages, typically with larger firms, and often in the form of sub-contracts, franchising, licensing and supplier relationships. Within these arrangements, large enterprises can often serve as a valuable source of capital, technology transfer, and quality collateral in the form of secure production contracts (Wattanapruttipaisan, 2002). MEs backward linkages in the value chain are normally with larger firms from which inputs, technology transfer, and training can be obtained. Horizontal linkages, on the other hand, are typically in the form of formal and informal networks with firms of similar size, either directly or through umbrella organizations and associations.

These strategies currently employed by IS/MEs, and that have been shown to significantly improve performance, are not captured in the current activity-based competitive business strategy typologies found in the strategic management literature. This may explain why membership within the Porter typology's strategic groups by MEs in this study may not have adequately captured the differences in their performance. In its current form, the typology may be too limiting by not sufficiently providing alternative strategy dimensions capturing strategies that have been shown to improve the performance of IS/MEs. . This, therefore, presents an opportunity for further research into the development of competitive business typologies directly derived from activities known to improve the performance of IS/MEs , and therefore be more applicable to them. .

\section{References}

Bacchetta, M., Ernst, E., \& Bustamante, J. P. (2009). Globalization and Informal Jobs in Developing Countries, International Labour Organisation and World Trade Organisation, Geneva.

Barkley, D. L., \& Henry, M. S. (2007). Rural Industrial Development: To Cluster or Not to Cluster? Review of Agricultural Economics, 19(2), 308-325.

Beal, R. M., \& Yasai-Ardekani, M. (2000). Performance Implications of Aligning CEO Functional Experiences with Competitive Strategies. Journal of Management, 26(4), 733-762.

Boohene, R. (2009). The Relationships among Gender, Strategic Capabilities, and Performance of Small Retail Firms in Ghana. Journal of African Business, 10(1), 121-138. https://doi.org/10.1080/15228910802701601

Chadamoyo, P., \& Dumbu, E. (2012). Competitive Strategy and Business Environment Influencing Performance of Small and Medium Enterprises in the Manufacturing Sector: The Case Study of Manufacturing Firms in Mucheke Light Industry. European Journal of Business and Management, 4(10).

Chen, M. (2005). Rethinking the Informal Economy: Linkages with the Formal Economy and the Formal Regulatory Environmen. Research Paper, UNU-WIDER, United Nations University, No. 2005/10.

Cochran. (1977). Sampling Techniques (3rd ed.). Wiley, New York.

Commission for Africa (CfA). (2005). Our common interest: report of the commission for Africa. DFID, London.

De Soto, H. (1989). The Other Path: The Economic Answer to Terrorism. Harper-Collins, New York.

Dess, G. G., \& Davis, P. S. (1984). Porter's (1980) generic strategies as determinants of strategic group membership and organizations performance. Academy of Management Journal, 27, 467-488.

International Labour Organisation (ILO). (1972). Employment, Incomes and Equality: A Strategy for Increasing Productive Employment in Kenya. ILO, Geneva.

International Labour Organization (ILO). (2000). Resolution concerning statistics of employment in the informal sector. adopted by the Fifteenth International Conference of Labour Statisticians (January 1993), in Current International Recommendations on Labour Statistics, 2000 edition, ILO, Geneva.

International Labour Organization (ILO). (2002). Women and men in the informal economy: a statistical picture, ILO, Geneva.

Kenya National Bureau of Statistics (KNBS). (2016). Statistical Abstracts and Economic Surveys 2016, KNBS, Nairobi. 
Kim, E., Nam, D., \& Stimpert, J. L. (2004). The applicability of Porter's generic strategies in the digital age: assumptions, conjectures, and suggestions. Journal of Management, 30(5), 569-589.

Kinyanjui, M. N. (2007). Emerging production systems in conventional development: experience of the jua kali economy in Kenya. Umoja, 2(2), 27-35.

Leitner, K. H., \& Guldenberg, S. (2010). Generic strategies and firm performance in SMEs: a longitudinal study of Austrian SMEs", Small Business Economics, 35(2), 169-189.

Lockett, A., \& Thompson, S. (2001). The resource-based view and economics. Journal of Management, 27, 723-754.

Maloney, W. F. (2004). Informality revisited. World Development, 32(7), 1159-1178.

Masakure, O., Henson, S., \& Cranfield. (2009). Performance of Microenterprises in Ghana: A Resource-Based View, Journal of Small Business and Enterprise Development, 16(3), 466-484. https://doi.org/10.1108/14626000910977170

Mungai, E., \& Ogot, M. (2012). Gender, Culture and Entrepreneurship. International Business Research, 5(5), 175-183. DOI:10.5539/ibr.v5n5p175

Muriuki, B. K. (2013). Micro and Small Restaurants in Nairobi's Strategic Response to their Environment. European Journal of Business and Management, 5(1), 170-178.

Ogot, M. (2014). Evidence of Challenges Faced by Manufacturing Informal Sector Micro-Enterprises in Nairobi and their Relationship to Strategic Choice. International Business Research, 7(6), 119-128. https://doi.org/10.5539/ibr.v7n6p119

Otoo, M., Ibro, G., Fulton, J., \& Lowen-Deboer, J. (2012). Micro-Entrepreneurship in Niger: Factors Affecting the Success of Women Street Vendors. Journal of African Business, 13(1), 16-28. https://doi.org/10.1080/15228916.2012.657937.

Pertusa-Ortega, E., Molina-Azorin, J. F., \& Claver-Cortes, E. (2009). Competitive strategies and firm performance: a comparative analysis of pure, hybrid or 'stuck in the middle' strategies in Spanish firms. British Journal of Management, 20, 508-523.

Porter, M. (1985). Competitive Advantage, Creating and Sustaining Superior Performance. New York: Free Press

Porter, M. E. (1980). Competitive strategy: Techniques for analyzing industries and competitors. New York: The Free Press.

Roy, M. A., \& Wheeler, D. (2006). A Survey of Mirco-Enterprise in Urban West Africa: Drivers shaping the sector. Development in Practice, 16(5), 452-464.

Spanos, Y. E., Zaralis, G., \& Lioukas, S. (2004). Strategy and industry effects on profitability: evidence from Greece. Strategic Management Journal, 25(2), 139-165.

Stevenson, L., \& St-Onge, A. (2005). Support for Growth Oriented Women Entrepreneurs in Kenya. International Labour Organization, Geneva.

Tokman, V. (1978). An Exploration into the Nature of the Informal-Formal Sector Relationship. World Development, 6(9/10), 1065-75.

Wattanapruttipaisan, T. (2002). SME Requirements as a Bridgehead to Competitiveness: An Assessment of Supply-Side Capabilities and Demand-Side Requirements. Asia-Pacific Development Journal, 9(1). 65-87.

Wernerfelt, A. (1984). A Resource-Based View of the Firm. Strategic Management Journal, 5(2), 171-180.

World Bank. (2005). Education sector strategy update. Achieving education for all, broadening our perspective, maximizing our effectiveness (December), World Bank, Washington.

Yan, S. (2010). Competitive Strategy and Business Environment: The Case of Small Enterprises in China. Asia Social Science, 6(11), 64-71.

\section{Copyrights}

Copyright for this article is retained by the author(s), with first publication rights granted to the journal.

This is an open-access article distributed under the terms and conditions of the Creative Commons Attribution license (http://creativecommons.org/licenses/by/4.0/). 